\title{
Impact of Clinical Pharmacy Services on Health-Related Quality of Life in Rheumatoid Arthritis Patients
}

\author{
${ }^{*}$ S. Kumaravel ${ }^{1}$, K. Jayaprakash ${ }^{1}$, Jincy John², Jiya Shaji², S. Karthika², K. Suvedha², Vandhana. A ${ }^{2}$ \\ ${ }^{1}$ Vivekanandha Medical Care Hospital, Tiruchengode, Tamil Nadu, India. \\ ${ }^{2}$ Swamy Vivekanandha College of Pharmacy, Tiruchengode, Tamil Nadu, India. \\ *Corresponding author's E-mail: shakthivelkumaravel@gmail.com
}

Received: 22-06-2020; Revised: 24-08-2020; Accepted: 30-08-2020.

DOI: $10.47583 /$ ijpsrr.2020.v64i01.038

\begin{abstract}
The objective of this study is to Assess the Impact of Clinical pharmacy services on Health-related quality of life in Rheumatoid Arthritis patients. The prospective observational study was conducted in 48 Rheumatoid Arthritis patients for a period of 3 months at Vivekanandha Medical Care Hospital, Elayampalayam. During baseline, patient data were collected, quality of life was assessed by using the SF-36 Questionnaire and Patient counselling was provided by using Patient information leaflet. At the second visit the same questionnaire was administered and the responses were documented finally, the comparative score was calculated and the improvement in the quality of life was assessed. Our study results show that there is a statistically significant difference between the baseline and follow up values for various domains of SF 36 questionnaire which implies that a remarkable improvement in the quality of life was observed in the patients affected with rheumatoid arthritis after providing clinical pharmacy services. Our study concludes that clinical pharmacist mediated services have an important role in improving the patient's health related quality of life.
\end{abstract}

Keywords: Clinical pharmacy services, Rheumatoid Arthritis, Health-related quality of life, SF-36 questionnaire.

\section{INTRODUCTION}

R heumatoid arthritis (RA) is a chronic, systemic autoimmune disease that involves inflammation in the membrane lining of the joints and often affects internal organs. Most patients exhibit a chronic fluctuating course of the disease that can result in progressive joint destruction, deformity, and disability. ${ }^{1}$ In addition individuals with RA experience varying degrees of physical impairment, fatigue, fever, reactive depression, and weight loss. ${ }^{2}$

Approximately over $1 \%$ of the population worldwide is affected by rheumatoid arthritis, with females are more commonly affected. The prevalence of rheumatoid arthritis increases with age in both sexes; nearly $5 \%$ of women and $3 \%$ of men over the age of 65 years are affected by the disease. The peak age of incidence is about 30-50 years in women and slightly older in men. ${ }^{3}$

Treatment with disease-modifying antirheumatic drugs (DMARDs) typically begins shortly after RA diagnosis. Different agents are currently available, including conventional or targeted synthetic DMARDs, and biologic DMARDs. Patients often also use NSAIDs and steroids to alleviate pain and swelling. ${ }^{4}$

The Quality of Life was defined by the world health organization as "an individual's perception of their position in life in the context of the culture and value systems in which they live with relation to their goals, expectations, standard and concerns" ${ }^{5}$

Quality of Life (QoL) is an important outcome in its own right, but also because it may influence the patient's selfcare activities, which may consequently impact their diabetes control. ${ }^{6}$ Health related quality of life instruments are available to measure the quality of life in rheumatoid arthritis. The instruments used to measure the quality of life are Health assessment questionnaire-disability index Short Form-36 (SF-36). ${ }^{7}$

SF- 36 is a 36 item scale which measures the 8 dimensions of an individual's health status (Physical functioning, Limitations due to physical health, Limitations due to emotional health, Bodily Pain, Vitality, Social Functioning, Mental health, and General health. ${ }^{8}$

The pharmacist plays a vital role in Rheumatoid arthritis including improving patient adherence, educating and counseling the patients about the disease and drugs. As per pharmaceutical care concept pharmacists play an imperative role in establishing patient relationships, obtaining medication history information, preventing, identifying and resolving medication related problems. ${ }^{9}$

\section{Literature Review}

- Mohanraj Rathinavelu Mudhaliar et al., 2016 conducted a prospective interventional study on Impact of Clinical Pharmacist Mediated Patient Counseling on Health Related Quality of Life in Rheumatoid Arthritis Patients. The study included a sample size of 64 patients who met the inclusion criteria. The questionnaires used were health assessment questionnaire for rheumatoid arthritis and SF-36 health survey. All the data's pertaining to questionnaires of Quality Of Life (QOL) were collected at the first and second visits of the patient. In this study, it was observed that there was a significant difference in the quality of life in 
rheumatoid arthritis patients in all the domains both physically and mentally after providing the patient education with the patient information leaflet and the mean quality of life score for baseline and follow up visits. This study concluded that pharmacist based patient education and counseling may have a greater positive impact on the quality of life in rheumatoid arthritis patients.

- Mark Kosinski et al., 2002 conducted a doubleblinded, randomized control trial study on the impact of disease and treatment response on health-related quality of life in early rheumatoid arthritis. The study included a total of 424 patients with early rheumatoid arthritis who were on etanercept or methotrexate. Patients were assessed for Health-related quality of life before and throughout treatment using the Medical Outcomes Study Short Form 36 Health Survey (SF-36) and the Health Assessment Questionnaire (HAQ). Before the start of treatment, rheumatoid arthritis patients showed significant decrements in scores on all SF-36 scales. After 52 weeks of treatment, 7 out of 8 SF-36 scales and the physical summary measure remained significantly below the general US population norm. Patients who were on etanercept showed significantly better HQL improvement earlier in treatment than patients with methotrexate treatment on the SF-36 physical summary. Patients showed no significant differences between treatment groups at 52 weeks. The study concluded that successful treatment from the beginning of rheumatoid arthritis showed improved health-related quality of life.

\section{METHODOLOGY}

\section{Study Design}

Prospective Interventional Study

\section{Study Centre}

The study entitled "Impact of Clinical Pharmacy Services on Health Related Quality of Life in Rheumatoid Arthritis Patients" was carried out in a 300 bedded multi-specialty tertiary care hospital (Vivekanandha Medical Care Hospital, Elayampalayam) with the approval (Ref. No: SVCP/IEC/AUG/2019/03 dated 31/08/2019) of the institutional ethical committee of Vivekanandha Medical Care Hospital, Elayampalayam.

\section{Department Selected for the Study in the Hospital}

The department selected for the study was Orthopedics.

\section{Study Duration}

The study was carried out in a period of 4 months (Aug 2019 - Nov 2019).

\section{Sample Size}

About 57 patients were screened and 46 were included in the study after getting the patient's consent.

\section{Selection of Study Subject}

$>$ Inclusion Criteria

- Patients who are willing to participate in the study

- Gender: Male and female

- $\quad$ Age $>18$ yrs

- Currently treating with RA drugs

$>$ Exclusion Criteria

- Pregnant and lactating women

- In patients

- Patients who are not willing to participate in the study

\section{Method}

Patients diagnosed with RA

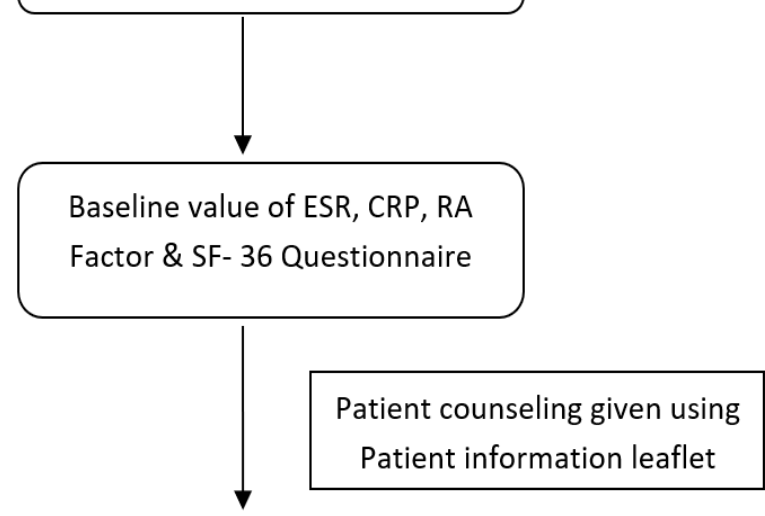

Follow-up value after 3 months

\section{Tool Used}

\section{SF - 36 RAND Questionnaire}

SF 36 (Short Form Health Survey) questionnaire was used to assess the Health-Related Quality of Life. A scoring algorithm is used to calculate the scores for the eight domains. Scores range from 0 to 100 with ' 0 ' corresponding to worst possible health and ' 100 ' corresponding to the best possible health. A patient information leaflet was designed to bring awareness about the quality of life in Rheumatoid arthritis and counselling was given after assessing the patient's quality of life.

\section{Statistical analysis}

The statistical analysis was done using Microsoft Excel and Graph Pad InStat DTCG (GPI v 3.0). The paired t-student test was used to analyze the significant difference between baselines and follow up by using Graph Pad InStat DTCG (GPI v 3.0). 


\section{RESULTS}

The study was conducted in 46 Rheumatoid arthritis patients in the department of Orthopedics at a 300 bedded tertiary care hospital.

\section{Gender}

Gender wise distribution of Rheumatoid arthritis is showed that 12 (26\%) were male patients and 34(74\%) were female patients.

Table 1: Gender wise distribution of Rheumatoid Arthritis Patients

\begin{tabular}{|c|c|c|c|}
\hline S. No & Sex & No. of Patients & Percentage \\
\hline 1 & Male & 12 & $26 \%$ \\
\hline 2 & Female & 34 & $74 \%$ \\
\hline
\end{tabular}

\section{Age}

Based on age categorization, 1 (2.2\%) patient belongs to age group of $20-30$ years, $5(10.9 \%)$ patients were within $30-40$ years, $23(53.5 \%)$ patients were within $40-50$ years, $12(26.1 \%)$ patients were within $50-60$ years and 5 (10.9) patients belongs to the age group of 60-70.

Table 2: Age Wise Distribution of Rheumatoid Arthritis Patients

\begin{tabular}{|c|c|c|c|}
\hline $\begin{array}{c}\text { S. } \\
\text { No }\end{array}$ & Age Category & $\begin{array}{c}\text { No of } \\
\text { Patients }\end{array}$ & Percentage \\
\hline 1 & $20-30$ & 1 & $2.2 \%$ \\
\hline 2 & $30-40$ & 5 & $10.9 \%$ \\
\hline 3 & $40-50$ & 23 & $53.5 \%$ \\
\hline 4 & $50-60$ & 12 & $26.1 \%$ \\
\hline 5 & $60-70$ & 5 & $10.9 \%$ \\
\hline
\end{tabular}

\section{Body Mass Index (BMI)}

Based on the BMI categorization 2 (4.4\%) patients were found to have underweight, 21 (45.7\%) have normal weight, 17 (37\%) patients were found to have overweight and $6(13.1 \%)$ were found to be obese.

Table 3: Body Mass Index of Rheumatoid Arthritis Patients

\begin{tabular}{|c|c|c|c|}
\hline S. & BMI Category & $\begin{array}{c}\text { No. of } \\
\text { Patients }\end{array}$ & Percentage \\
\hline 1 & Underweight & 2 & $4.4 \%$ \\
\hline 2 & Normal weight & 21 & $45.7 \%$ \\
\hline 3 & Overweight & 17 & $37 \%$ \\
\hline 4 & Obese & 6 & $13.1 \%$ \\
\hline
\end{tabular}

\section{Co-morbidities}

Among 46 patients, out of all the co-morbidities observed, HTN with 18 patients (39\%) stands first. Next comes $\mathrm{T}_{2} \mathrm{DM}$ with 15 patients (33\%), $9(20 \%)$ patients were found to have both HTN and $\mathrm{T}_{2} \mathrm{DM}, 4$ (9\%) patients have Thyroid disorders.
Table 4: Co-Morbidities among Rheumatoid Arthritis Patients

\begin{tabular}{|c|c|c|c|}
\hline S. & Co-morbidities & $\begin{array}{c}\text { No. of } \\
\text { Patients }\end{array}$ & Percentage \\
\hline 1 & HTN & 18 & $39 \%$ \\
\hline 2 & T2DM $_{2}$ & 15 & $33 \%$ \\
\hline 3 & HTN \& T2DM & 9 & $20 \%$ \\
\hline 4 & Thyroid disorders & 4 & $9 \%$ \\
\hline
\end{tabular}

\section{Health Related Quality of Life Assessment}

Health Related Quality of Life of the patients was assessed using SF-36 RAND questionnaire. The SF-36 scores at the baseline and after 90 days are given below. At baseline the mean domain scores for the SF-36 were lower. At the end of 90 days the patient's quality of life scores were found to be improved.

Table 5: SF-36 Domain scores at Baseline and after 90 Days

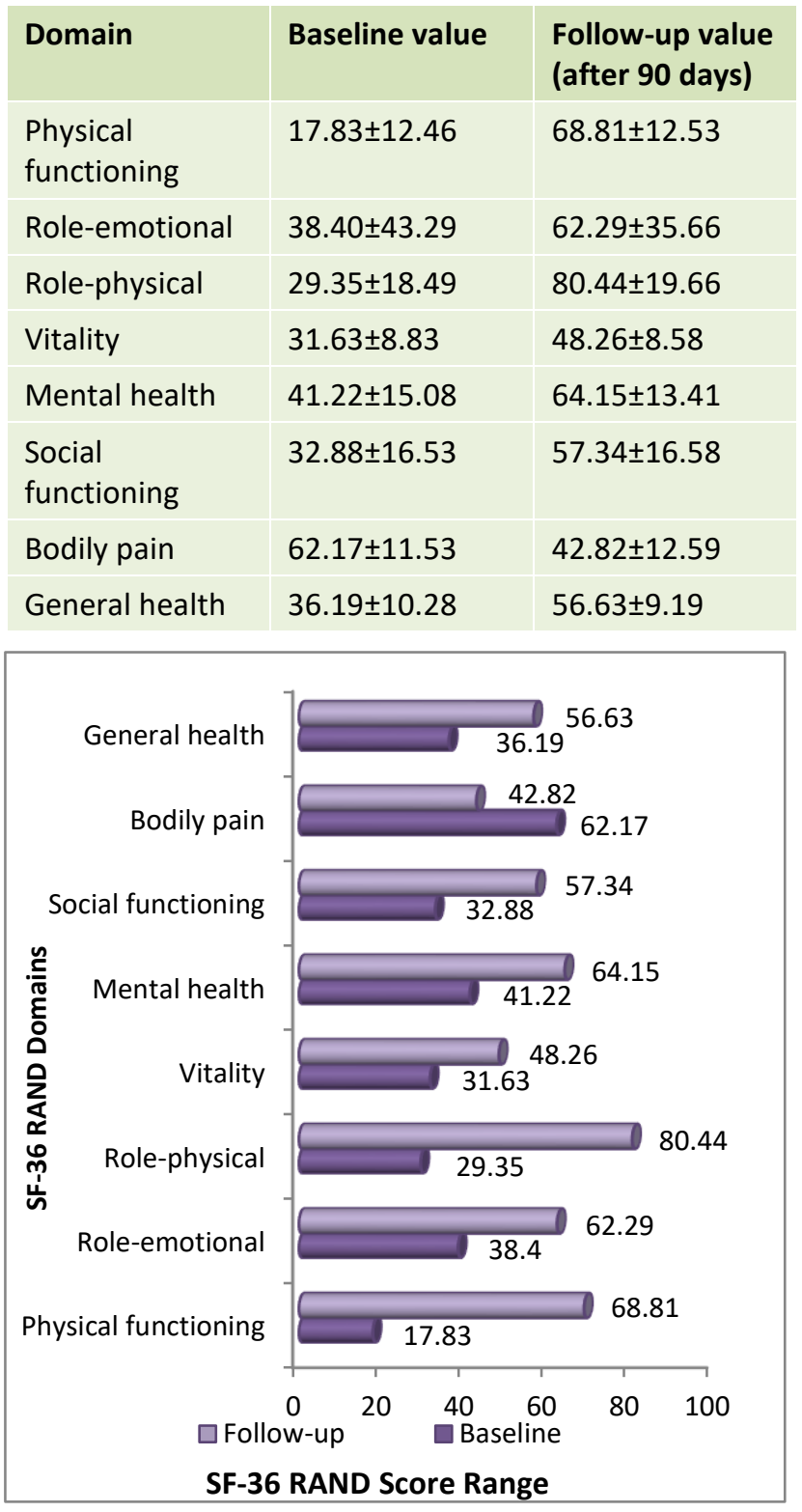

Figure 4: SF-36 Domain scores at Baseline and after 90 Days ('p' Value $<0.0001$ ) 
Comparative Responses to Quality of Life SF-36 Health Survey in Baseline and Follow-Up in Terms of Health Outcome

Health care outcomes such as Erythrocyte sedimentation rate, Rheumatoid factor and $\mathrm{C}$ reactive protein were assessed in all patients at baseline and follow up. Patient education regarding life style changes that should be adapted in an RA patient was provided and assessed. Mean scores showed a statistically significant decrease from the baseline values.

Table 6: Comparative Responses to Quality of Life SF-36 Health Survey in Baseline and Follow-Up in Terms of Health Outcome

\begin{tabular}{|c|c|c|c|c|}
\hline S. No & Variables & Baseline Value & Follow-up Value & ' $\boldsymbol{p}$ ' Value \\
\hline 1 & Erythrocyte Sedimentation Rate (ESR) & $48.17 \pm 24.50$ & $41.50 \pm 24.63$ & 0.0092 \\
\hline 2 & Rheumatoid Factor (RF) & $25.23 \pm 9.61$ & $21.35 \pm 8.58$ & $<0.0001$ \\
\hline 3 & C-Reactive Protein (CRP) & $23.38 \pm 9.55$ & $20.54 \pm 8.49$ & $<0.0001$ \\
\hline
\end{tabular}

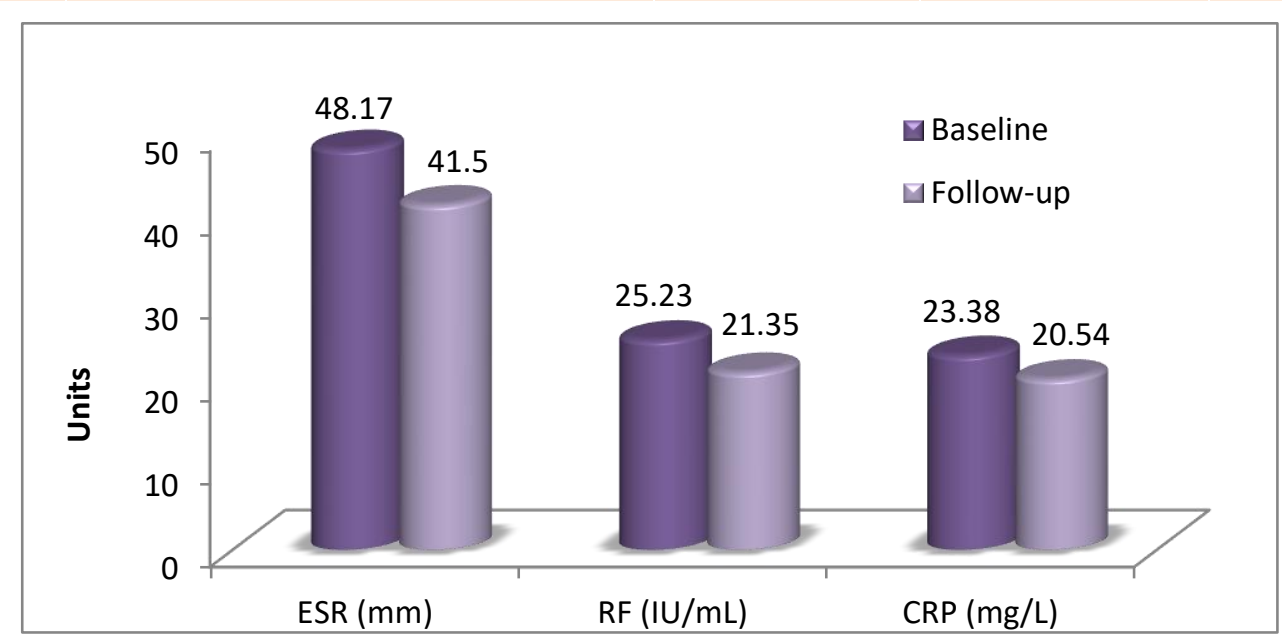

Figure 5: Comparative Responses to Quality of Life SF-36 Health Survey in Baseline and Follow-Up in Terms of Health Outcome

\section{DISCUSSION}

Rheumatoid arthritis a chronic, progressive disease characterized by joint pain, stiffness and deformities on multiple regions affects and places patients at a risk of early death. With the progression of disease, patient starts experiencing difficulty in carrying out their day to day activities which can impair the quality of life. ${ }^{10}$

In our study majority of the patients with Rheumatoid arthritis who were enrolled belongs to the age group of 40 $50(53.5 \%)$ followed by the age group of $50-60(26.1 \%)$. Baseline data shows that affected females (74\%) were about thrice the male patients (26\%). The above data indicates that increasing age as well as female gender was important risk factors for the incidence of RA. Our study also found that patients among the category of normal weight were more prone to RA than overweight as well as obese patients. These results were consistent with the findings in the study conducted by Mudhaliar et al., on Impact of clinical pharmacist mediated patient counseling on HRQOL in RA patients. ${ }^{9}$

Majority of the patients had Hypertension (39\%) and 33\% patients hadT $\mathrm{T}_{2} \mathrm{DM}$ as their co morbidity where as $20 \%$ of the patients had both. Similar results were observed in a study conducted on Impact of clinical pharmacist mediated patient counseling on HRQOL in RA patients by Mudhaliar et al. ${ }^{9}$

In this study Health related quality of life of the patients were assessed by using SF 36 questionnaire and patient education was provided to improve their quality of life. Health related quality of life scores showed significant improvement from the baseline values for the further follow up among the 8 domains in majority of the patients. Physical functioning, Role limitations due to physical health and bodily pain were the domains which showed a major difference between the baseline and follow up scores. Their respective scores were Physical functioning (17.83 \pm 12.46 and $68.81 \pm 12.53)$, Role limitations due to physical health $(29.35 \pm 18.49$ and $80.44 \pm 19.66)$ and Bodily pain (62.17 \pm 11.53 and $42.82 \pm 12.59$ ). HRQOL scores among the patients of our study for the other domains at Baseline and follow-up were Role limitations due to emotional health (38.4 \pm 43.29 and $62.29 \pm 35.66)$, vitality (31.63 \pm 8.83 and $48.26 \pm 8.58)$, Mental health $(41.22 \pm 15.08$ and $64.15 \pm 13.41)$, Social functioning ( $32.88 \pm 16.53$ and $57.34 \pm 16.58)$, General health $(36.19 \pm 10.28$ and $56.63 \pm 9.19)$. The overall $p$ value was 0.001 which signifies that the results were statistically significant. The above results were consistent with the observations found in the study conducted by Mark 
Kosinski et al. ${ }^{2}$ on Impact of disease and treatment response on HRQOL in early RA patients.

Health outcome measures like ESR, Rheumatoid factor and $C$ reactive protein were also studied during baseline and follow up session. All the parameters showed a significant decrease from the baseline for the follow up session. Baseline and follow up values were ESR $(48.17 \pm 24.50$ and 41.50 \pm 24.63$)$, Rheumatoid Factor (25.23 \pm 9.61 and $21.35 \pm 8.58)$ and CRP (23.38 \pm 9.55 and $20.54 \pm 8.49)$ which were similar to the results obtained in a study conducted by M R Mudhaliar et al., ${ }^{9}$ on Impact of clinical pharmacist mediated patient counseling on HRQOL in RA patients.

The overall results convey that Clinical pharmacy services have an important impact on health care outcomes like ESR, CRP, Rheumatoid factor and Health related quality of life among Rheumatoid arthritis patients.

\section{CONCLUSION}

Rheumatoid Arthritis an autoimmune disorder affects and impairs the quality of life of the patients such that they face difficulty in meeting their basic requirements as well as trouble them emotionally and socially. Our study results like other similar studies are of the same view point that incorporation of a clinical pharmacist mediated pharmacy services to the treatment can improve the quality of life among Rheumatoid Arthritis patients over various aspects like physical, emotional and social status. Hence our study concludes that clinical pharmacy services have a positive impact on the patient's health related quality of life.

\section{REFERENCES}

1. Shargel L, Mutnick A, Souney P, Swanson L. Comprehensive pharmacy review: Osteoarthritis and Rheumatoid arthritis, $8^{\text {th }}$ ed, 2013, 863-873

2. Mark Kosinski, Sara C, Richard Martin, Lee. A, Mary C, John E, Eleanor M. Health-related quality of life in early rheumatoid arthritis: Impact of disease and treatment response, The American journal of managed care. 8, 2012, 231-241.
3. Walker $\mathrm{R}$, Whittlesea $\mathrm{C}$, Clinical pharmacy and therapeutics, $5^{\text {th }}$ ed, Edinburgh, Churchill Livingstone, 2012, 832-843

4. Marengo $M$, Suarez-Almazor $M$. Improving treatment adherence in patients with rheumatoid arthritis: what are the options?, International Journal of Clinical Rheumatology, 10, 2015, 1-12.

5. Mudhaliar M, Yiragamreddy S, Ghouse I, Patta J, Tabula $U$, Kumar P, Impact of Clinical Pharmacist Mediated Patient Counseling on Health Related Quality of Life in Rheumatoid Arthritis Patients in Healthcare Resource Limited Settings of India. Indian Journal of Pharmacy Practice, 9, 2016, 247-252.

6. Sriram. S, Suresh Damodharan, Akhila S. Arjun, Latha Nandipati Raghuram. Impact of pharmaceutical care activities on diabetic patients at a private corporate hospital, International Journal of Medical Research \& Health Sciences, 5, 2016, 66-74.

7. Michael M. Ward, Lori C. Guthrie, Maria I. Alba, Clinically important changes in short form 36 health survey scales for use in Rheumatoid arthritis in clinical trials the impact of low responsiveness. Arthritis Care and Research, 66, 2014, 1783-1789.

8. Vanessa Burhoit, Paul Nash. Short form 36 (SF36) Health Survey Questionnaire: normative data for Wales. Journal of Public Health, 33, 2011, 587-603.

9. Mohanraj Rathinavelu Mudhali, Samhitha Reddy Yiragam Reddy, Ishrar Shaik Mohammad Ghouse, Javeed Patta, Ushanandhini Tabula, Praveen Kumar, Impact of clinical pharmacist mediated patient counselling on health related quality of life in rheumatoid arthritis patients in healthcare resource limited settings of India. Indian journal of pharmacy practice, 9, 2018, 247-252.

10.Pier Nuccio Scutellaria, Carlo Orzincolo. Rheumatoid arthritis: sequences. European journal of Radiology, 27, 1998, 31-38.

Source of Support: None declared.

Conflict of Interest: None declared.

For any question relates to this article, please reach us at: editor@globalresearchonline.net

New manuscripts for publication can be submitted at: submit@globalresearchonline.net and submit_ijpsrr@rediffmail.com 